\title{
Numerical simulation of geostress and support of roadway crossing strata in complex stress condition
}

\author{
Tongxu Wang ${ }^{1, a}$, Laiyuan $\mathrm{Li}^{2}$, Wenhai Zheng ${ }^{1,3, b}$, Yang Liu ${ }^{1, \mathrm{c}}$, Tao Hou ${ }^{4}$ \\ and Hongyuan $\mathrm{Qu}^{5}$ \\ ${ }^{1}$ Shandong University of Science and Technology, 579 Qianwangang Road Economic \& Technical \\ Development Zone, Qingdao Shandong Province, China, 266590 \\ ${ }^{2}$ Geting coal mine, Shandong energy Zibo mining Group Co.,LTD.,Ershilipu Rencheng Jining \\ Shandong Province, China,272053 \\ ${ }^{3}$ Institute of Mechanics, Chinese Academy of Sciences, No.15 Beisihuanxi Road, Beijing, China, \\ 100190 \\ ${ }^{4}$ Tangkou coal mine, Shandong energy Zibo mining Group Co.,LTD.,Nanzhang Rencheng Jining \\ Shandong Province,China,272055 \\ ${ }^{5}$ Beijing Huayu engineering Co., LTD, China Coal Technology and Engineering Group, 67 Ande \\ road Xicheng Beijing, China,100120 \\ a wtx6383@163.com, b zwh1208@163.com, ' Ixly1220@163.com
}

Keywords: Complex stress condition, Numerical simulation of geostress, Roof structure detection, Stability Classification

\begin{abstract}
Affected by a group of underground chambers and gobs of working faces, the track sub-inclined shaft of 430 mining area in Geting coal mine, which crosses coal seam and faults repetitively, lies in high and complex stress environment. Based on geostress results measured in the field, FLAC ${ }^{3 \mathrm{D}}$ numerical simulation software was used to simulate the regional geostress in the area near the roadway, referring to the impact of the gobs and chambers. And the stress variation law along the roadway was given at last. Then the roadway roof structure zone chart was drawn according to the detection results with the rock video detection recorder. Finally, stability of different sections of the roadway and the support advice corresponding to each section was gained. The results show that comprehensive consideration of geostress variation law and surrounding rock structure is necessary in the stability classification and the support of roadways. The research methods and ideas given in this paper is feasible.
\end{abstract}

\section{Project Overview}

Usually, the track sub-inclined shaft lies in a complex stress environment. The rock structure changes constantly thus the stability is different in each section [1-3]. In this condition, it's hard to do the roadway support, while the support patterns and parameters are also change accordingly. The common support pattern is bolt-shotcrete and arch metal stent [4-7].

The track sub-inclined shaft of 430 mining area in Geting coal mine nearby gobs of coal face 2321 and 2319 which set across coal seam and fault repetitively, is under a group of underground chambers, and the vertical distance of nearest position is only $8.7 \mathrm{~m}$ (point $\mathrm{M}$ shown in figure 1 (a)). The spatial relationship is shown in figure 1 and figure 2.

In order to study the stability of track sub-inclined shaft and provide reasonable supporting and reinforcement measures to ensure roadway construction safety and long-term stability, this paper used FLAC $^{3 \mathrm{D}}$ numerical simulation software to simulate the regional geostress field. Referring to the impact of some factors such as fault, gobs and chambers, it gave the stress variation law along the roadway. Then combined to the detection results of roadway roof structure, stability classification and partition of the roadway was put forward. The support advice corresponding to each section was also given. 

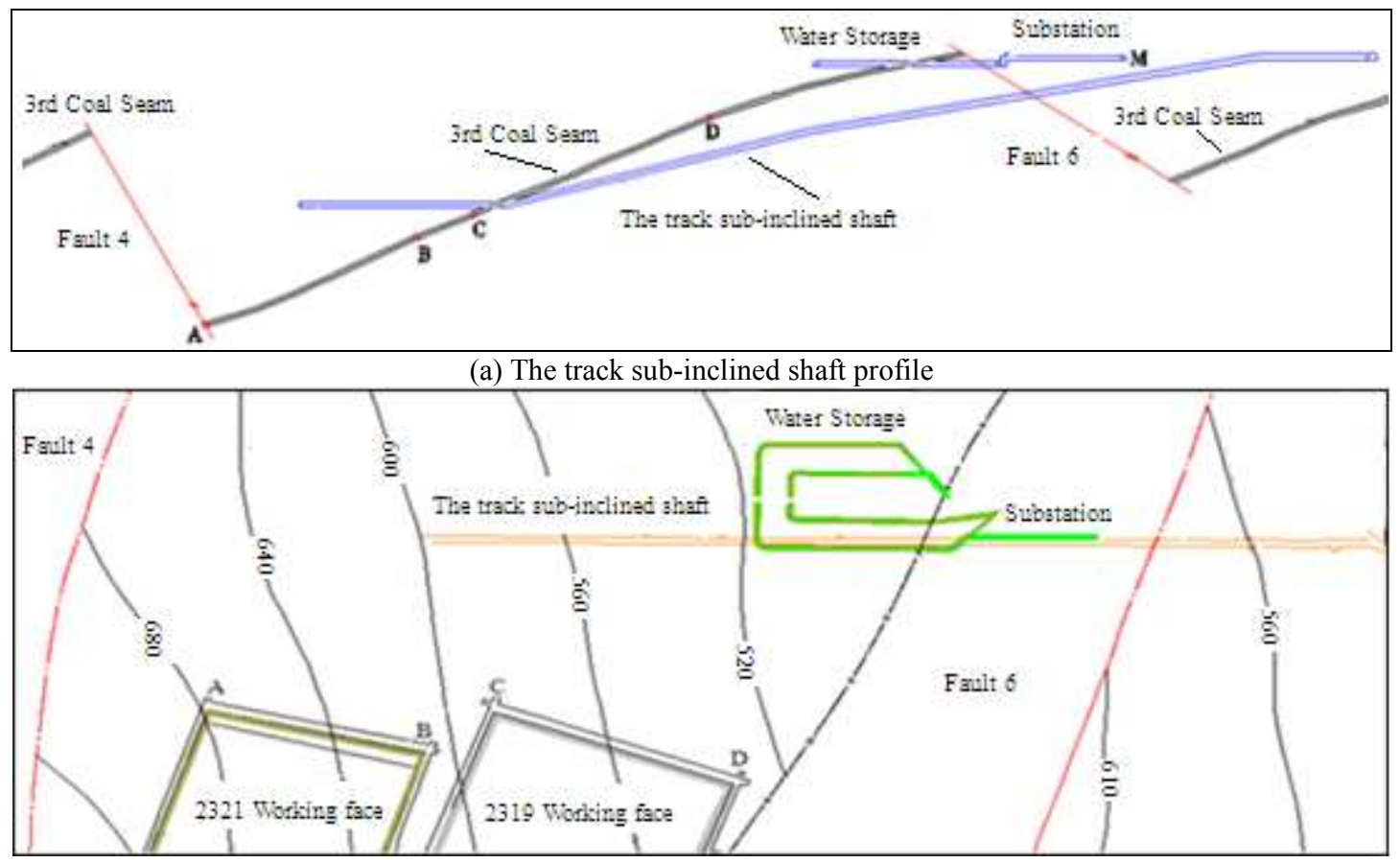

(b) The track sub-inclined shaft planar graph

Figure 1 The track sub-inclined shaft location schematic diagram

\section{Numerical simulation of geostress}

Consider the geological structure, lithology, rock seam angle, gobs nearby, excavation of underground chambers and other factors, the model size is $1000 \mathrm{~m}$ (length) $\times 300 \mathrm{~m}$ (width) $\times 300 \mathrm{~m}$ (height) which is shown in figure 2 and from which the spatial relationship between roadway and fault, coal seam can be easily got. Material model is defined as the Mohr-Coulomb model.

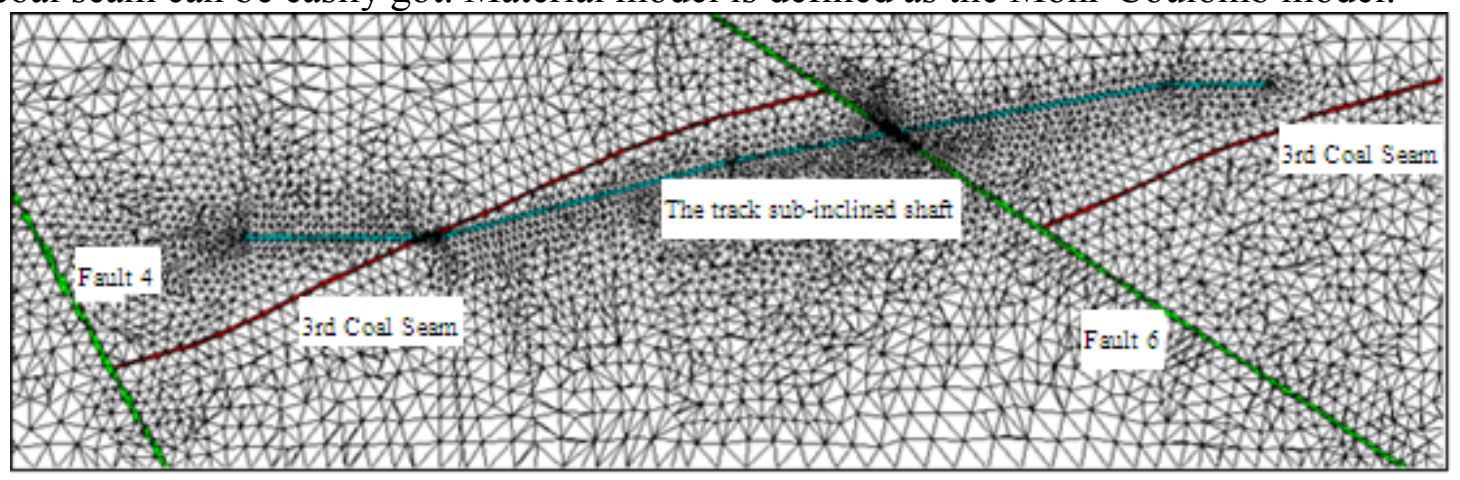

Figure 2 Model and mesh

There is a geostress measured point in the region and the measured results are shown in table 1. In order to well fit stress results of the measured point, each boundary of this model is fixed in normal direction.

Table 1 Error analysis of simulated and measured value

\begin{tabular}{|c|c|c|c|c|c|c|c|}
\hline \multirow[b]{2}{*}{$\begin{array}{l}\text { Measured value } \\
\text { (Mpa) }\end{array}$} & \multirow[b]{2}{*}{$\begin{array}{l}\text { Inclination } \\
\text { Azimuth }\end{array}$} & \multicolumn{2}{|c|}{$\begin{array}{c}\text { maximum } \\
\text { principal stress }\end{array}$} & \multicolumn{2}{|c|}{$\begin{array}{l}\text { intermediate principal } \\
\text { stress }\end{array}$} & \multicolumn{2}{|c|}{$\begin{array}{l}\text { minimum principal } \\
\text { stress }\end{array}$} \\
\hline & & -20.77 & $\begin{array}{l}19.3^{\circ} \\
239.4^{\circ}\end{array}$ & -11.37 & $\begin{array}{c}52.1^{\circ} \\
122.7^{\circ}\end{array}$ & -8.56 & $\begin{array}{l}-31.2^{\circ} \\
161.6^{\circ}\end{array}$ \\
\hline $\begin{array}{l}\text { Simulated value } \\
\qquad(\mathrm{Mpa})\end{array}$ & & -20.36 & & -11.56 & & -8.72 & \\
\hline Error & & $1.98 \%$ & & $1.67 \%$ & & $1.87 \%$ & \\
\hline
\end{tabular}

First, set initial stress in the model referring to the measured data, and then adjust constantly until the simulation results fit with the measured results in the corresponding point. The error between simulated and measured value is shown in table 1 . And the geostress direction is still determined by the measured results. 
After the original geostress simulation, excavate the part of working faces and underground chambers. And the final stress distribution was obtained after calculation termination.

The final principal stress cloud chart of the track sub-inclined shaft is shown in figure 3 . According to table 1 , the maximum principal stress direction is inclination of $19.3^{\circ}$ and azimuth of $239.4^{\circ}$ in this region, which is nearly horizontal and accord with the direction of track sub-inclined shaft, therefore it has little influence on the stability of the roadway. In contrast, the intermediate principal stress (inclination of $52.1^{\circ}$, azimuth of $122.7^{\circ}$ ) has more impact on it, its direction is generally vertical. Therefore, the intermediate principal stress is considered as the primary study object.

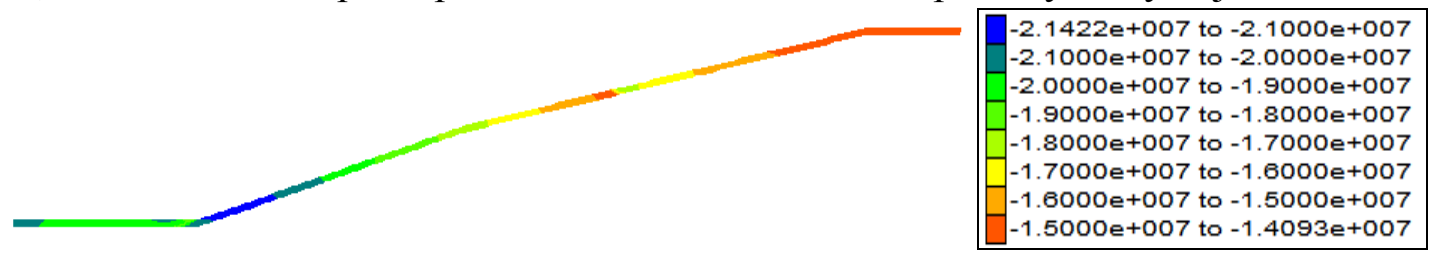

(a) The maximum principal stress

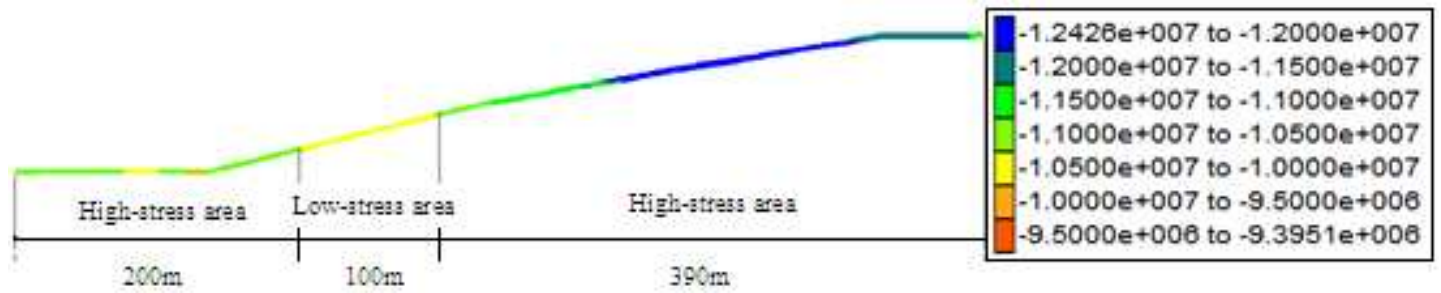

(b) The intermediate principal stress

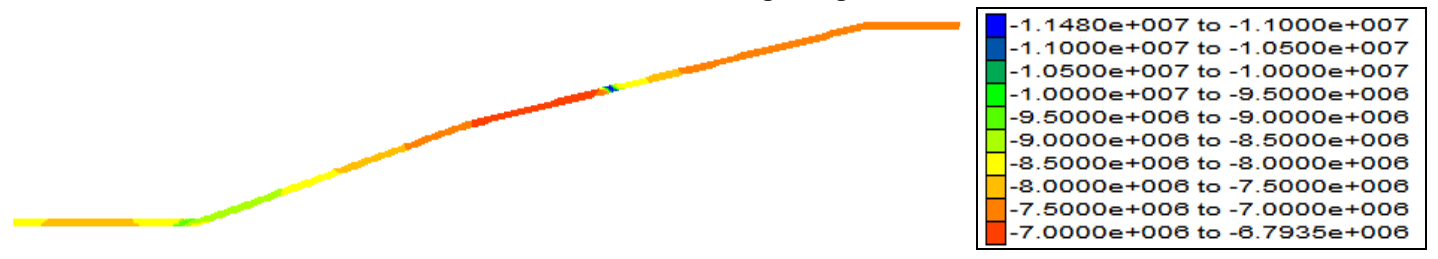

(c) The minimum principal stress

Figure 3 Roadway principal stress contour $(\mathrm{Pa})$

According to figure 3(b), the roadway was divided into high-stress area and low-stress area. In the high-stress area, the intermediate principal stress is $10.5 \sim 12.4 \mathrm{MPa}$ and in low-stress area $9.4 \sim 10.5$ $\mathrm{MPa}$.

\section{The field detection and analysis of roadway roof structure}

In order to observe roof layered and crack development along the track hidden inclined shaft, the rock video detection recorder was used. Six detection holes along the track hidden inclined shaft was set (as shown in figure 4). The roof structure was summarized and classified as shown in table 2.

Table 2 The track sub-inclined shaft roof classification statistics

\begin{tabular}{cccc}
\hline & & \multicolumn{2}{c}{ Roof structure } \\
\cline { 3 - 4 } number & $\begin{array}{c}\text { Detecting } \\
\text { depth }(\mathrm{m})\end{array}$ & In range of bolt anchorage $(0-2 \mathrm{~m})$ & Out range of bolt anchorage $(2-7 \mathrm{~m})$ \\
\hline $1 \#$ & 6.8 & $0-2.0 \mathrm{~m}$ crack development & No crack development \\
$2 \#$ & 6.4 & $0-1.0 \mathrm{~m}$ crack development & No crack development \\
$3 \#$ & 6.5 & No crack development & No crack development \\
$4 \#$ & 6.5 & No crack development & No crack development \\
$5 \#$ & 2.75 & $0-2.0$ m crack development & crack development \\
$6 \#$ & 5.7 & $0-1.8$ m crack development & No crack development \\
\hline
\end{tabular}

On the view of roof control, the roadway was divided into the complete structure area (no crack development within roof anchor) and the weak structural area (crack development within roof anchor), shown in figure 4 (the dark part shown in figure 4 is the crack development). Visibly, most of the area along the roadway is weak structure roof and poor stability. 


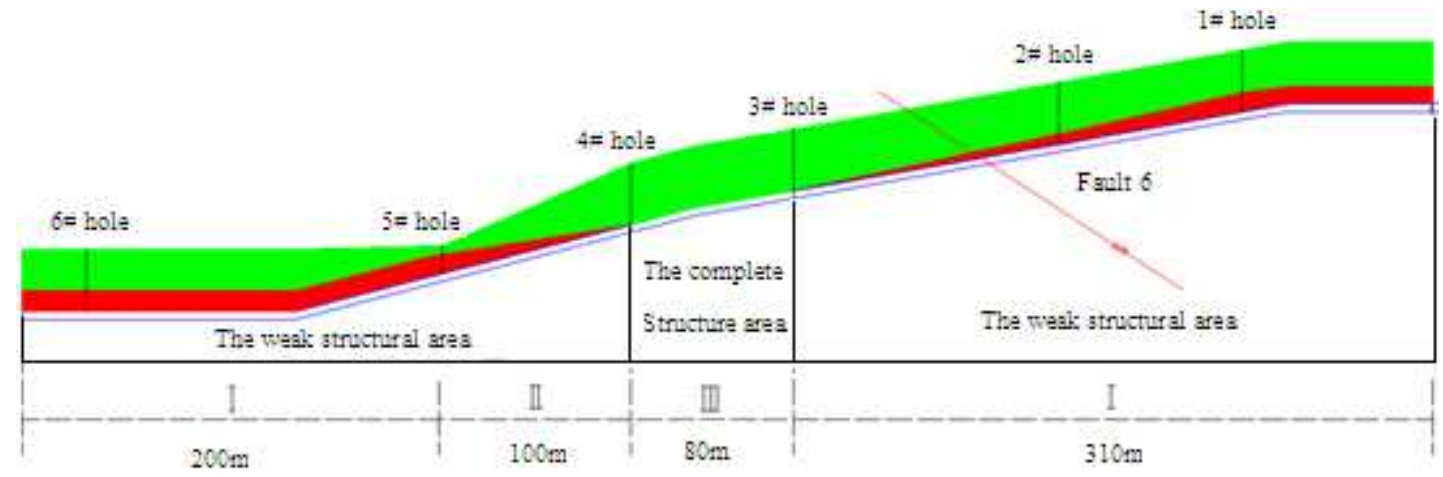

Figure 4 The track sub-inclined shaft roof structure classification

\section{The track sub-inclined shaft stability classification and support}

According to surrounding rock stress and roof structure partition of the track sub-inclined shaft, the stability of the roadway was divided into three categories as shown in Figure 4: (I) weak structure of high stress, (II) weak structure of low-stress, (III) complete structure of high stress.

For each type of roadway, supporting schemes and processes were provided as follows: (I) weak structure of high-stress sections. Support with bolt-shotcrete and arch metal stent, row spacing $1.0 \mathrm{~m}$, (II) weak structure of low-stress section. Support with bolt-shotcrete and arch metal stent, row spacing $1.5 \mathrm{~m}$, (III) complete structure of high stress section. Support with bolt-shotcrete.

\section{Acknowledgements}

This work was financially supported by the National Nature Science Foundation of China(51004068).

\section{Literature References}

[1] Alka. Agrawal: A hidden fault. Popular Science. New York, Vol. 254 (1999).

[2] RAWNSLEY. K.: Joint development in perturbed stress field near fault .J.Struct. Geol, (1992).

[3] Pande G. N. Beer G. and Williams J.R.: Numerical methods in rock mechanics, Wiley, New York. (1990).

[4] Zienkiewicz O.C., Valliappan S.and King I.P.: Stress analysis of rock as a "no-tension" material,Geotechnique,Vol.18,56-66. (1968).

[5] Yunfang Liu, etc: Hubei Science \& Technology Press. (2000). (In Chinese)

[6] Bin Ma: Master's degree thesis of Tianjin university. (2003). (In Chinese)

[7] Tongxu Wang, Wenhai Zheng and Saijiang Liang: Numerical Simulation of Regional Stress Field under Complex Geological Condition, ICCET, (2011). 
Trends in Civil Engineering

10.4028/www.scientific.net/AMR.446-449

Numerical Simulation of Geostress and Support of Roadway Crossing Strata in Complex Stress Condition

10.4028/www.scientific.net/AMR.446-449.1781 